\title{
Thoracoscopic spine surgery for decompression and stabilization of the anterolateral thoracolumbar spine
}

\author{
Amin Amini, M.D., M.Sc., Rudolf Beisse, M.D., And Meic H. Schmidt, M.D. \\ Department of Neurosurgery, University of Utah, Salt Lake City, Utah; and Department of Trauma \\ Surgery, Berufsgenossenschaftliche Unfallklinik Murnau, Germany
}

\begin{abstract}
The anterior thoracolumbar spine can be exposed via a variety of approaches. Historically, open anterolateral or posterolateral approaches have been used to gain access to the anterior thoracolumbar spinal column. Although the exposure is excellent, open approaches are associated with significant pain and respiratory problems, substantial blood loss, poor cosmesis, and prolonged hospitalization. With the increasing use of the endoscope in surgical procedures and recent advances in video-assisted thoracoscopic surgery, minimally invasive thoracoscopic spine surgery has been developed to decrease the morbidity associated with open thoracotomy. The purpose of this article is to illustrate the surgical technique of a minimally invasive thoracoscopic approach to the anterolateral thoracolumbar spine and to discuss its potential indications and contraindications in patients with diseases involving the anterior thoracic and lumbar regions.
\end{abstract}

\section{KeY WordS - endoscopic spinal surgery - thoracoscopy - thoracic spine • lumbar spine - thoracoscopic spinal instrumentation}

Since the introduction of thoracoscopic surgery by Jacobaeus $^{15}$ in 1910, the technique has undergone enormous advances. With the development of high-quality video imaging, small endoscopes, and modified new instruments, video-assisted thoracic surgery has become the minimally invasive technique of choice for most thoracic and transthoracic surgeries. As our experience and success with video-assisted thoracic surgery has grown, surgeons have recently begun to apply the technique to thoracic spine surgery. $1,16,23,30,31$

Traditionally, thoracolumbar diseases in need of surgery required an open thoracotomy or a thoracoabdominal exposure of both the thoracic cavity and the retroperitoneal space. Alternatively, a retropleural thoracotomy or a lateral extracavitary approach was used to gain access to the anterior thoracic or lumbar spine., 2,6,12,29 These open approaches require extensive incisions, muscle dissection, and rib resections to provide adequate surgical exposure of the anterior thoracolumbar spine. In 1993, Mack, et al. ${ }^{18}$ first reported their experience of thoracoscope-assisted spine surgery. This was followed by the report by McAfee, et al., ${ }^{21}$ which described the safety and potential complications of thoracoscopic and laparoscopic surgery for the anterior thoracolumbar spine. In 2002, Khoo, et al., ${ }^{16}$ reported the outcome of thoracoscopic spine surgery in 371 trauma patients with thoracolumbar fractures. Today, the indications for thoracoscopic anterior spine surgery have expanded enormously to include spinal biopsy procedures, debridement, discectomy, decompressive corpectomy, interbody fusions, and internal fixations.

Abbreviation used in this paper: $\mathrm{VB}=$ vertebral body.
Minimal access surgical techniques can potentially decrease spinal access morbidity and speed recovery and healing. ${ }^{4,7,16,17}$ At the University of Utah Medical Center, we have performed 30 thoracoscopic spine surgeries for thoracolumbar trauma, tumors, and infection. The purpose of this article is to review the surgical technique, indications, and contraindications of a minimally invasive thoracoscopy-assisted approach to the thoracolumbar spine.

\section{SURGICAL TECHNIQUE}

\section{Preoperative Evaluation}

In addition to regular spinal studies, preoperative radiographic evaluation should routinely include posteroanterior and lateral chest radiographs to evaluate for potential pleural fluid, fibrinous membranes, or adhesions in the pleural space. Recent myocardial infarction or significant arrhythmia should be ruled out by an electrocardiogram. In addition, routine preoperative laboratory work should include the coagulation parameters, serum electrolytes, blood group typing, and platelet count.

\section{Anesthetic Considerations and Positioning}

Thoracoscopic spine surgery is performed after induction of general endotracheal anesthesia. Patients are intubated using a double-lumen endotracheal tube to achieve singlelung ventilation for maximal surgical exposure. Alternatively, a single-lumen tube and an endotracheal blocker can be used if double-lumen endotracheal intubation cannot be achieved. The correct position of the endotracheal tube is confirmed with a bronchoscope before and after final posi- 
tioning. In addition, a Foley catheter and arterial and central venous lines are placed.

The patient is placed in a lateral decubitus position on a radiolucent table (Fig. 1), and is secured to the operating table with a four-point support system to the sacrum, pubic bone, scapula, and sternum. The legs are flexed slightly, an inflatable axillary roll is placed under the axilla, and the top arm is placed on a Krause armrest. At this point, the C-arm fluoroscope is brought into position and is used to ensure that the patient and the spine are perpendicular to the operating table. In general, a left-sided approach is preferred for access to the thoracolumbar junction (T11-L2) and a rightsided approach for the middle to upper thoracic spine (T310). It is essential, however, to individualize the side of the approach based on the vascular anatomy (aorta, vena cava) visualized on the preoperative computerized tomography studies.

\section{Thoracoscopic Access and Exposure}

After the patient is positioned optimally, the $\mathrm{C}$-arm fluoroscope is used to obtain the lateral spine image. The involved VBs, discs, anterior spinal line, and posterior spinal line are marked on the skin overlying the lateral chest wall (Fig. 1). Four access sites (portals) are then outlined around the level of the lesion. The position of the portals is crucial for optimizing working distances, image quality, and retraction. The working portal is centered directly over the level of the lesion. The portal site for the endoscopic camera is placed approximately two to three intercostal spaces away from the working portal in the direction of the cranium along the axis of the spinal column for pathological conditions in the thoracolumbar junction. Alternatively, in middle to upper thoracic spine cases, the portal for the endoscope can be placed caudal to the working portal. The suction/irrigation portal is located in a ventral and slightly cranial direction to the working portal. The fourth portal for the retractor of the lung and the diaphragm is placed ventral and slightly caudal to the working portal.

After the lateral spine anatomy is outlined and the portal sites are marked, the entire lateral chest well is prepared and draped for a full thoracotomy. It is important to consider and be prepared for the possibility of converting to an open thoracotomy if necessary. To minimize the risk of inadvertent injuries to underlying structures during the placement of the access sites, the first portal is placed at the site farthest away from the diaphragm by using a minithoracotomy technique, after the single-lung ventilation has been initiated.

The first portal site is opened using a blunt dissection technique to minimize possible injury to the lung. The subcutaneous tissues and intercostal muscles are dissected bluntly without removing any rib, which minimizes local trauma. The pleural space is then exposed and palpation is used to detect any pleural adhesions. The parietal pleura is opened under direct visualization to ensure proper lung deflation. Once this structure is opened and the lung is deflated securely, the first trocar is inserted and the $30^{\circ}$ endoscope is introduced into the thoracic cavity. After the thoracic cavity has been inspected, the remaining three trocar sites are placed under direct endoscopic visualization. The key anaomical structures (spine, diaphragm, and aorta or vena cava) are identified and the endoscopic image is oriented so that the spine is parallel to the lower edge of the video monitor (Fig. 2). The diaphragm usually inserts at the T12-L1 level. The diaphragm can be opened endoscopically if sur-

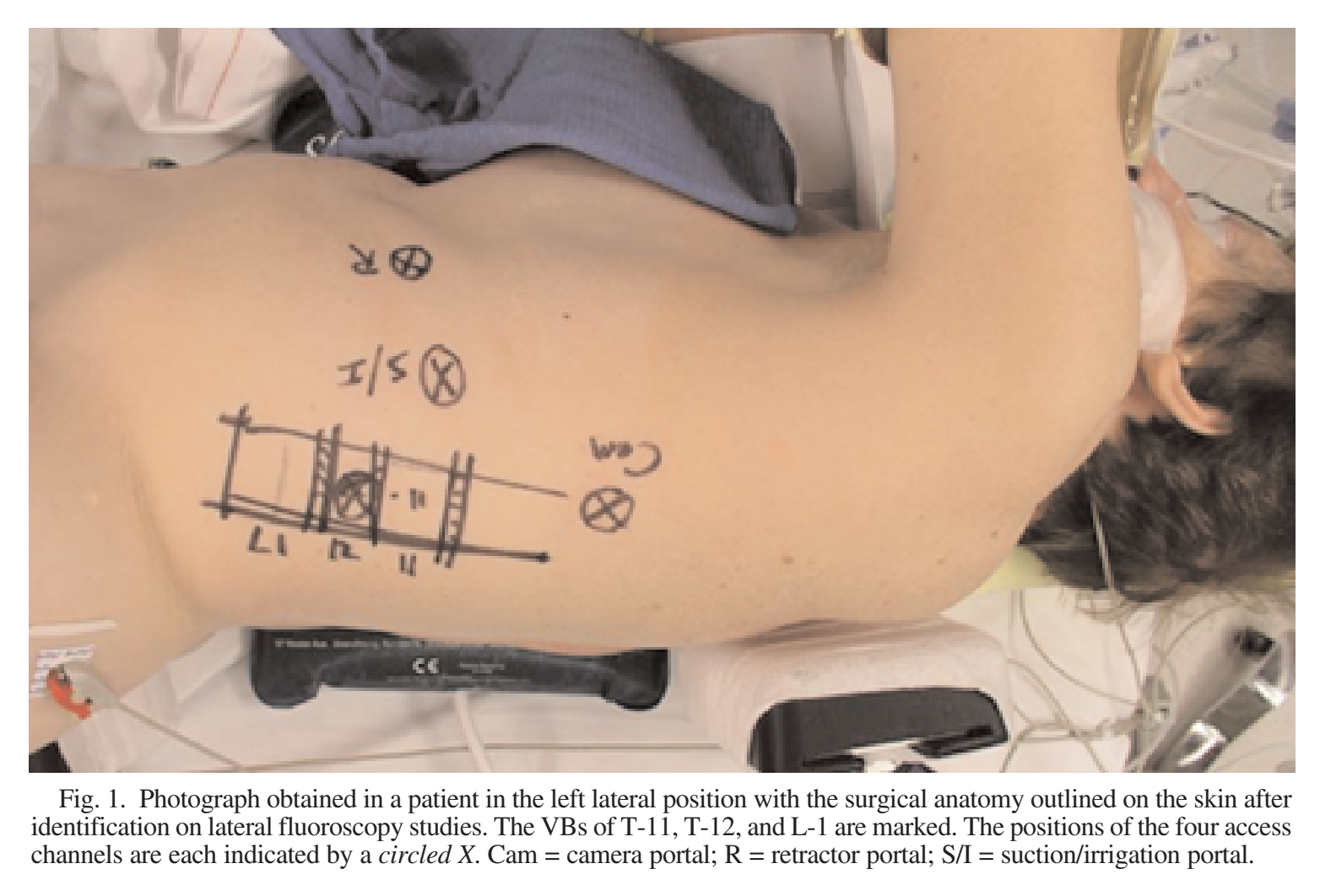




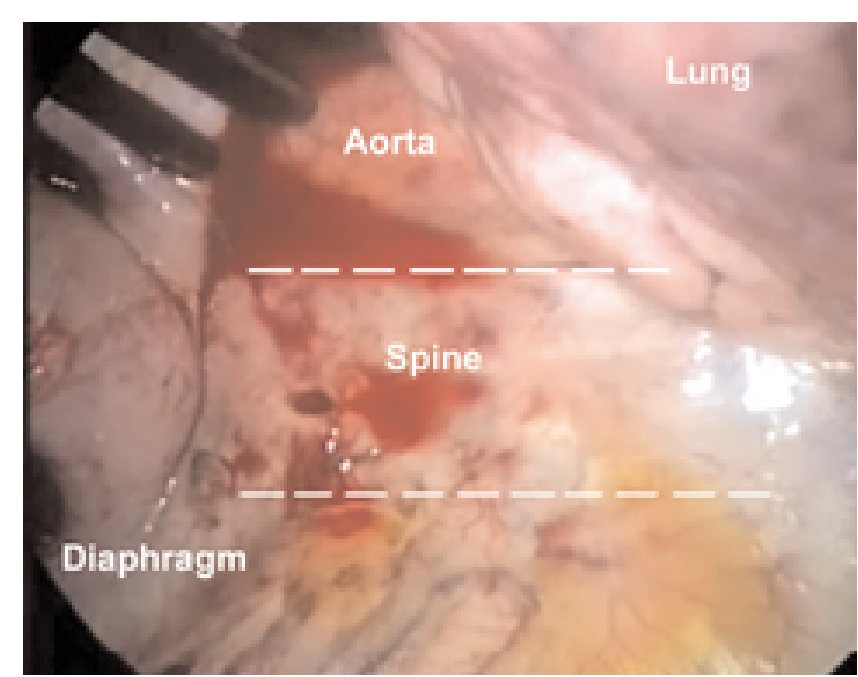

Fig. 2. Intraoperative photograph showing the endoscopic view of the exposure of the left thoracolumbar junction.

gical exposure below the insertion of the diaphragm is needed. ${ }^{4,17}$ The incision is usually placed 1 to $2 \mathrm{~cm}$ away from the diaphragmatic insertion site where the diaphragm naturally thins out. For the semicircular incision, we prefer using the harmonic scalpel, because it does not generate heat and smoke, which can impair endoscopic visualization. For exposure of L-1 and L-2, the diaphragm is opened farther caudally for up to $5 \mathrm{~cm}$. Although instrumentation can be implanted in L-3 by using a thoracoscopic approach, we prefer an endoscopic retroperitoneal exposure. After the diaphragm has been split, the retroperitoneal fat and peritoneal sac are bluntly dissected away from the fascia of the psoas muscle to expose the VBs.

After identification of the involved levels by using fluoroscopy, K-wires are placed in the VBs that are to receive instrumentation (Fig. 3; see also Endoscopic Anterolateral Stabilization). This greatly assists the surgeon in maintaining orientation in a two-dimensional operating field.

For exposure of the thoracic VBs and the intervertebral discs, a pleural flap must be elevated (Fig. 4A). The segmental vessels of the operative field lie transversely across the midportion of the VB deep to the parietal pleura (Fig. 4B). The harmonic scalpel with its hooklike tip is used to elevate and incise the parietal pleura. Then, the pleura is bluntly dissected and the segmental vessels are identified, ligated, and divided. This exposes the lateral VB wall and discs.

\section{Discectomy and Corpectomy}

Endoscopic discectomy and corpectomy are performed in the same steps as in an open procedure. The adjacent discs are incised with an endoscopic knife and removed with rongeurs. The intervening VB is removed by performing a median corpectomy with straight and curved osteotomes (Fig. $5)$. The corpectomy can be widened with osteotomes or a Midas Rex drill equipped with a coarse diamond drill bit. The depth of the corpectomy across the midline is controlled by observing it on fluoroscopic images. For spinal canal decompression, it is then necessary to identify the ipsilateral pedicle, which requires the removal of the rib head in the middle and upper thoracic spine. The neural foramen is identified at the base of the pedicle. The lateral spinal canal is then exposed by removing the pedicle with endoscopic punches. In cases of infection, metastatic tumor, and chronic inflammation, the epidural granulation tissue can be adherent to the dura mater and surrounding tissues, requiring careful dissection.

Reconstruction depends on the extent of the bone defect. For small defects, such as a discectomy defect, we prefer the placement of an iliac crest autograft or allograft. For larger defects, such as those resulting from a complete corpectomy, a larger interbody allograft can be placed (Fig. 6A). Alternatively, an expandable cage like the Synex cage can be used (Fig. 6B). In particular, the expandable cage can be used for interbody distraction if there is significant kyphotic deformity.

\section{Endoscopic Anterolateral Stabilization}

For endoscopic anterolateral stabilization, we use the
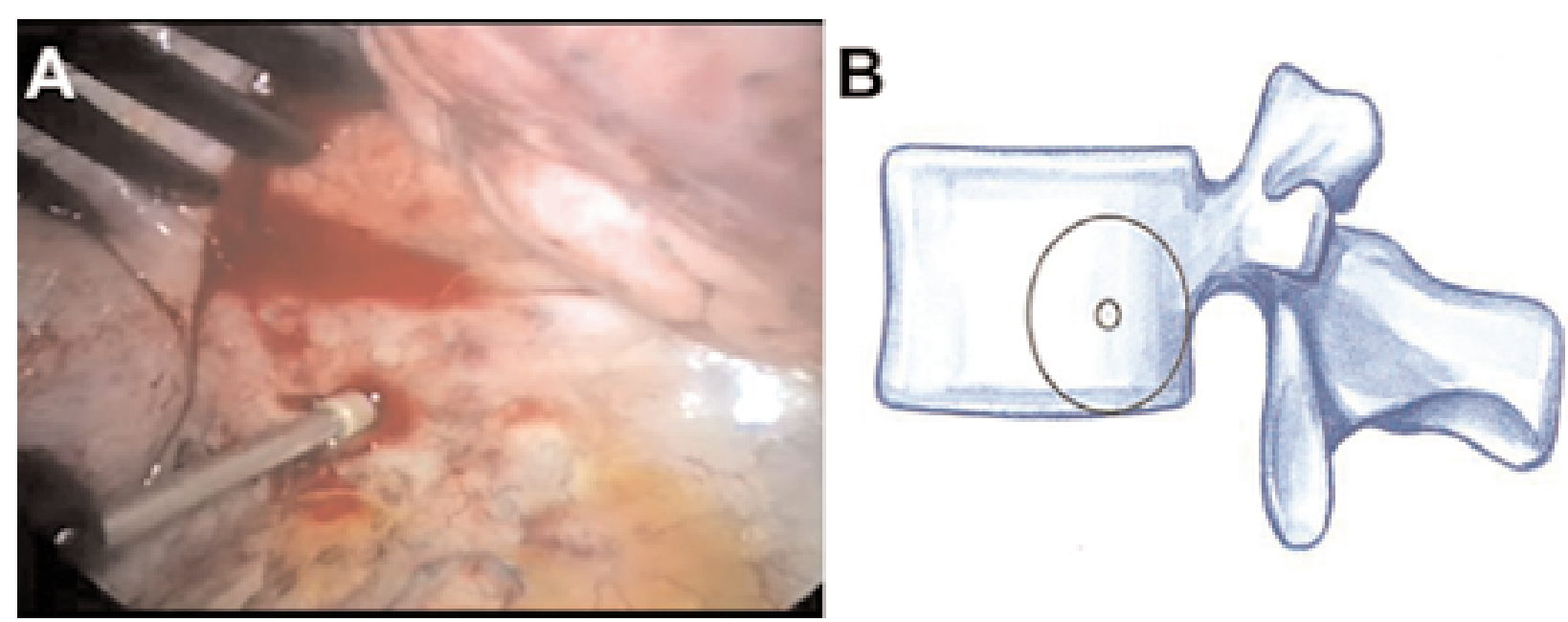

Fig. 3. A: Intraoperative photograph depicting the endoscopic placement of the K-wire by using the C-arm with the 
A. Amini, R. Beisse, and M. H. Schmidt

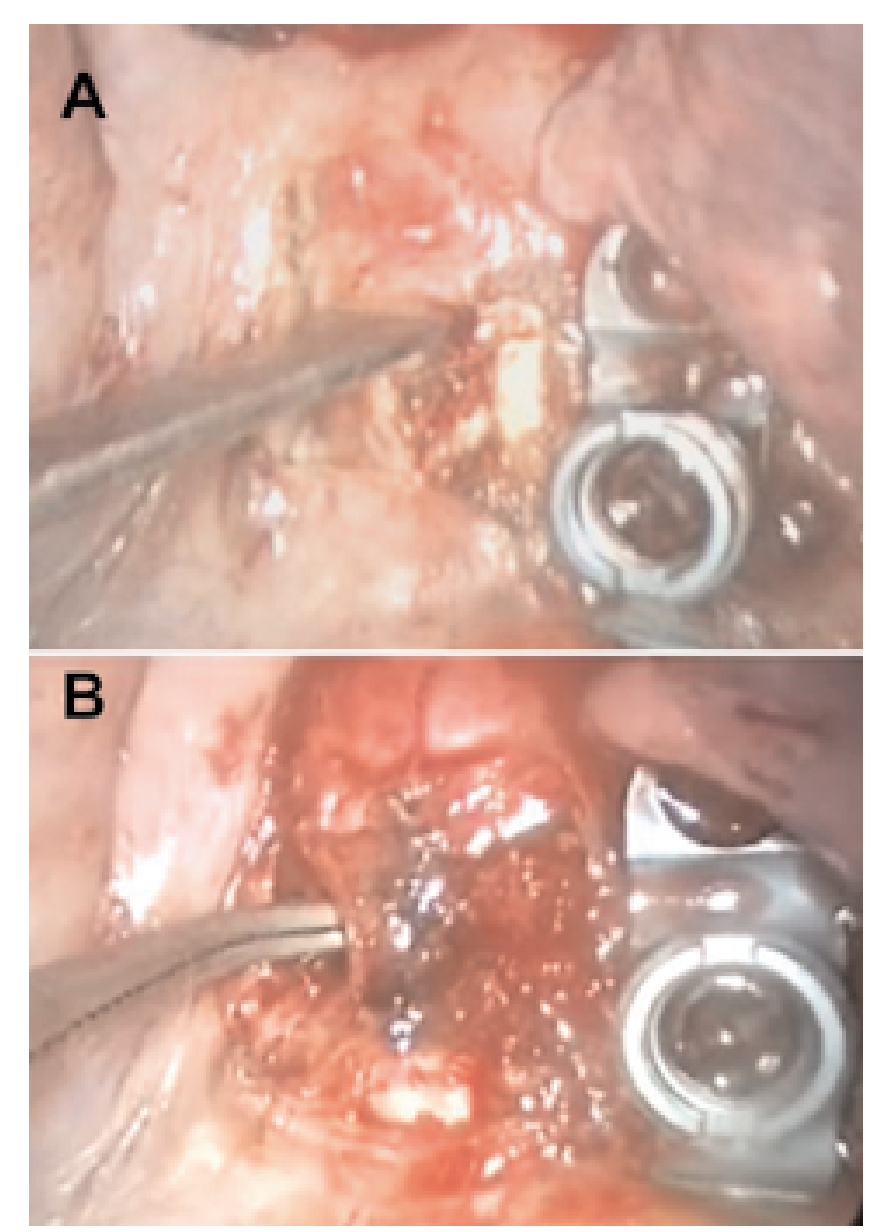

Fig. 4. Intraoperative photographs showing the elevation of the parietal pleura (A) and exposure of the segmental artery (B).

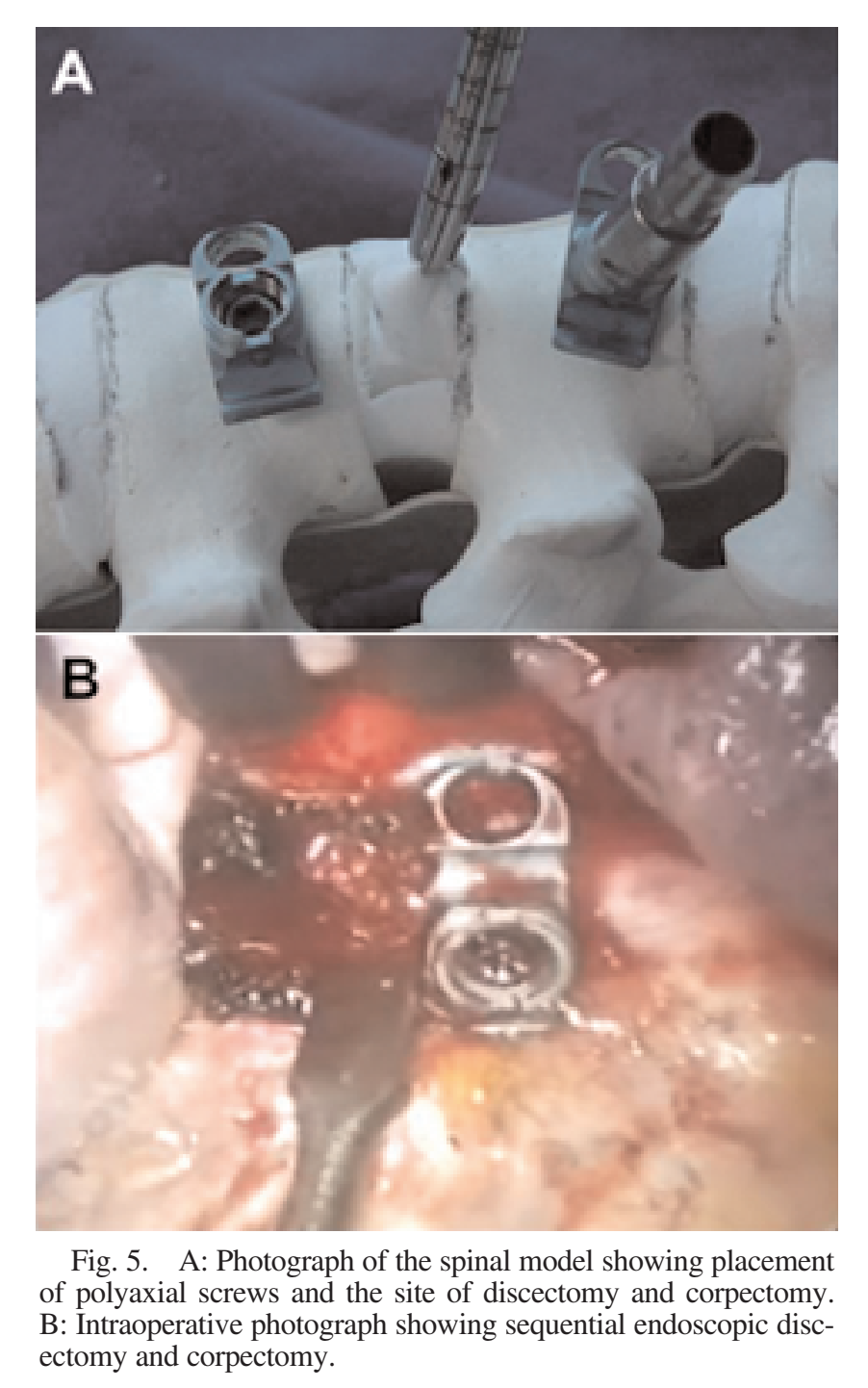

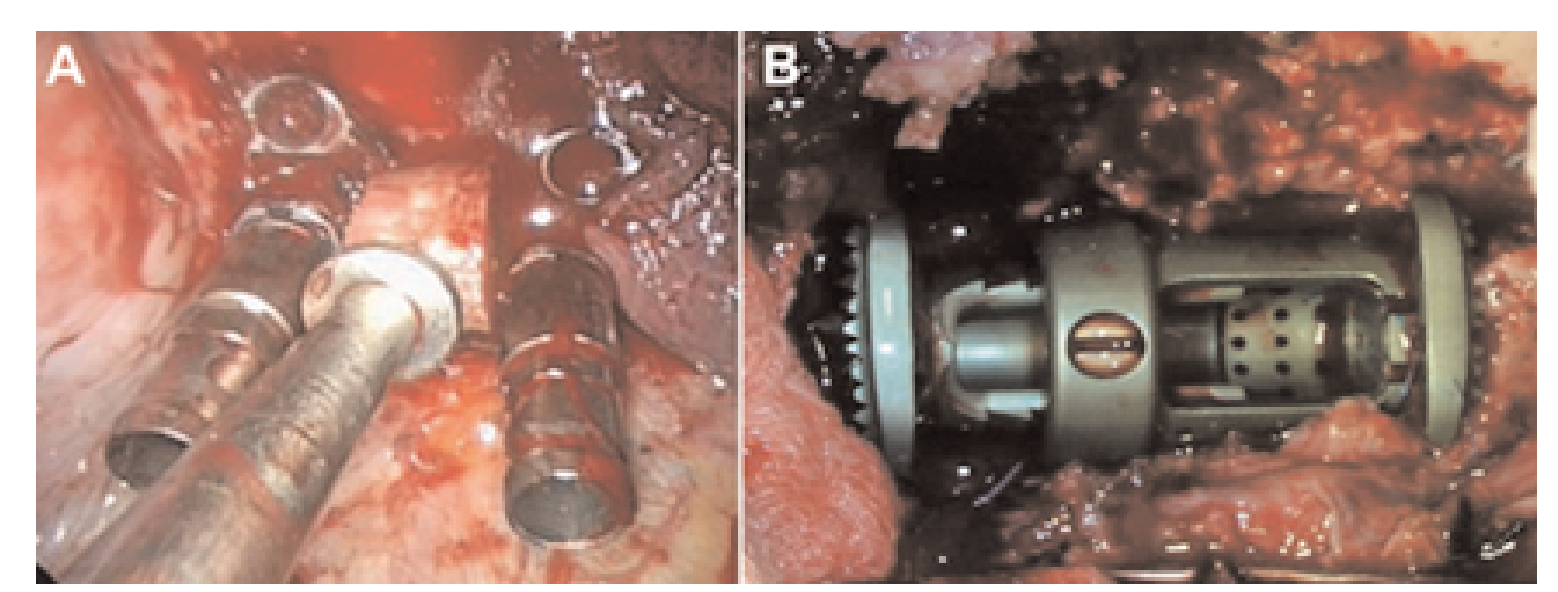

Fig. 6. Intraoperative photographs showing endoscopic bone graft impaction (A) and expandable cage placement (B). 
MACS-TL system. The entry point of the posterior screw is $10 \mathrm{~mm}$ anterior to the spinal canal in the upper or lower third of the VBs. Using the radiolucent impaction/targeting device, a short K-wire is placed under lateral fluoroscopy at the entry point (Fig. 7). A cannulated awl is then passed over the K-wire to decorticate the entry point. The polyaxial screw-clamp assembly is inserted, and the K-wire is removed after the screw has been engaged (Fig. 8). After both posterior screws have been placed, the length of the plate is determined using the endoscopic expandable measurement device, and the plate is placed over the polyaxial screws (Fig. 9). The plate is secured and then the anterior screws are inserted with a specialized aiming device (Fig. 10). The screw plate assembly is then locked. The screw and plate position are confirmed with additional anteroposterior fluoroscopic images (Fig. 11).

\section{Closure and Postoperative Care}

The diaphragmatic incision should be reapproximated with one or two sutures. Smaller incisions in the diaphragm $(<4 \mathrm{~cm})$ may not require primary closure. The thoracic cavity is then irrigated and a small No. 20 French chest tube is placed through one of the portal sites. The lung is reinflated under direct endoscopic vision, and the remaining portal sites are closed. The chest tube is routinely removed on the 1st postoperative day and a chest x-ray film is obtained to rule out pneumothorax.

\section{ILLUSTRATIVE CASE}

This 78-year-old woman sustained a T-12 burst fracture during a motor vehicle accident. The burst fracture resulted in a $15^{\circ}$ local kyphotic deformity and $25 \%$ canal compromise (Fig. 12). The patient was neurologically intact after the injury and was treated with a thoracolumbar brace and observation. She underwent this treatment for 11 months,

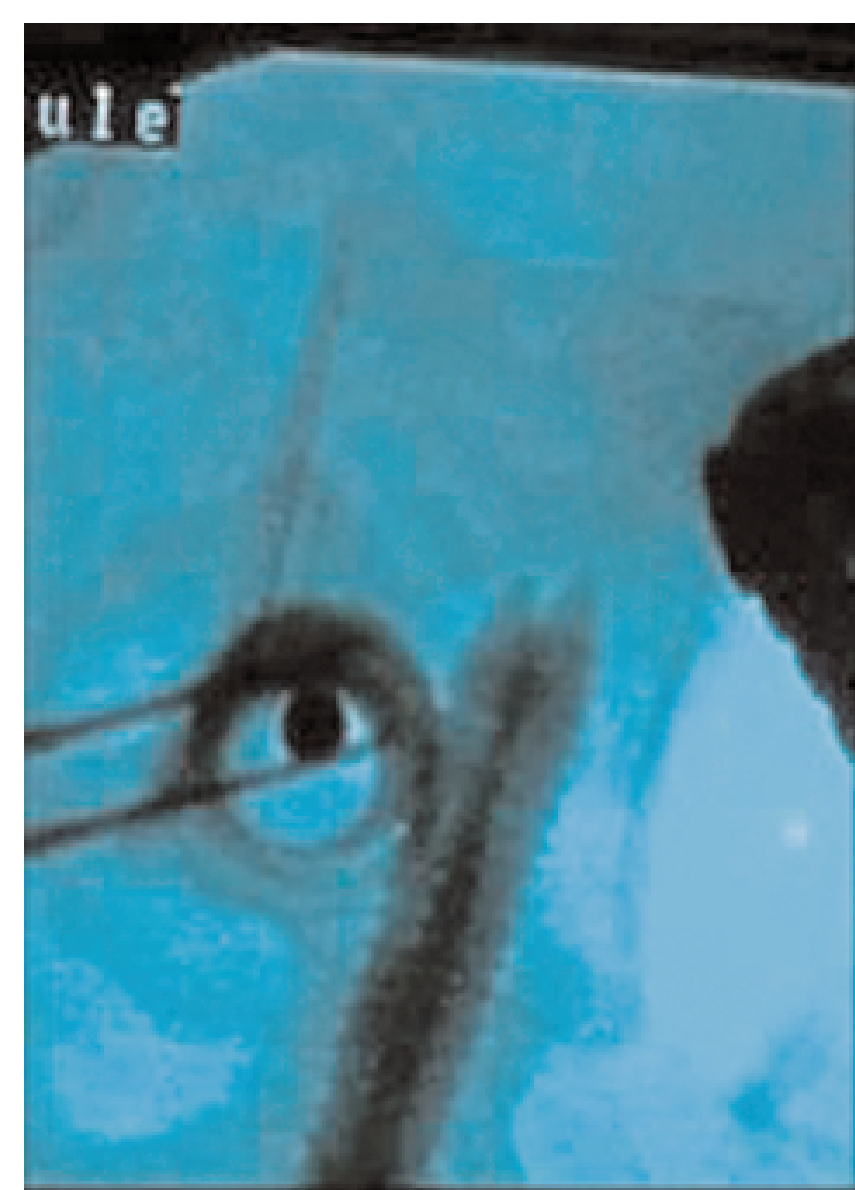

Fig. 7. Placement of the K-wire at the entry point under lateral fluoroscopy and direct endoscopic visualization.

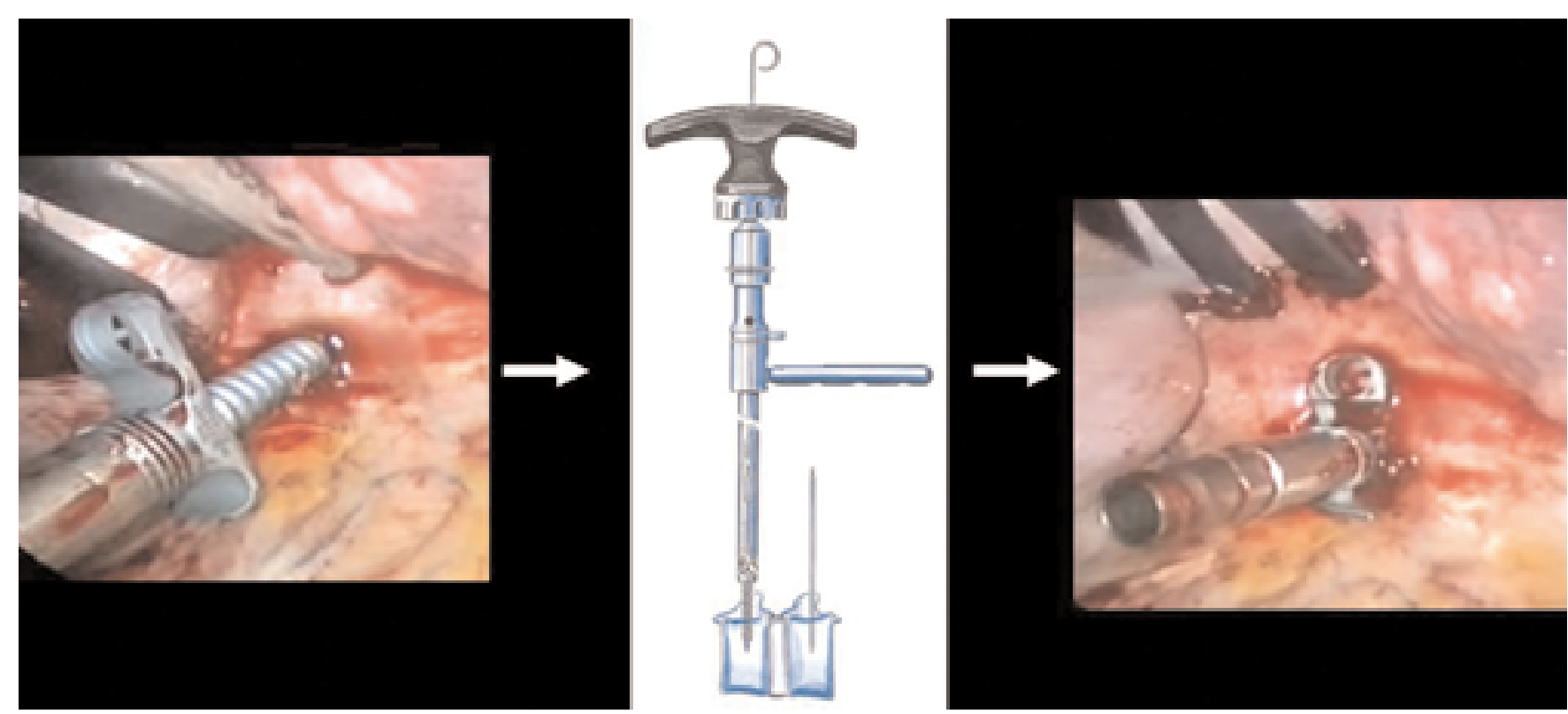

Fig. 8. Intraoperative photographs and drawing showing placement of a polyaxial screw over the K-wire and removal of the K-wire. 


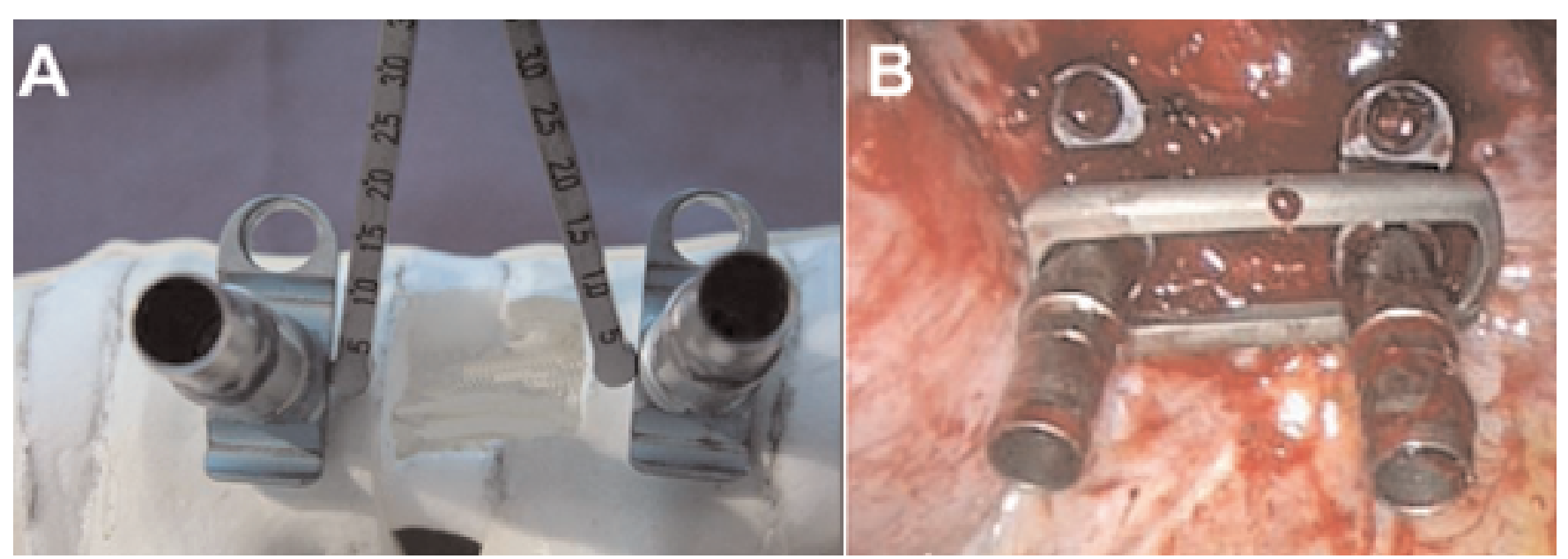

Fig. 9. A: Photograph of a model showing measurement of the size of the plate by using an expandable endoscopic device. B: Intraoperative photograph showing placement of the plate over the polyaxial screws.

but during this time worsening back pain and bilateral lower-extremity numbness slowly developed. Radiographic studies showed nonunion of the T-12 burst fracture. After full discussion, the patient elected to proceed with thoracoscopic surgical treatment.

The patient underwent a left T11-12 thoracoscopic discectomy with allograft bone fusion and instrumentation and stabilization with an MACS-TL plate system. Postoperative fluoroscopic images show the plate position (Fig. 11B). The patient was mobilized on the 1st postoperative day, after the chest tube had been removed, and chest x-ray films confirmed the absence of a pneumothorax. She was discharged on postoperative Day 3. At her 1-year follow-up visit, the patient was pain free and $\mathrm{x}$-ray films demonstrated a solid fusion.

\section{DISCUSSION}

Significant surgical morbidity has been associated with open anterior thoracic and thoracolumbar spinal surgery, including infection, muscle atrophy, chest wall dysfunction, shoulder dysfunction, respiratory difficulties, chronic postthoracotomy pain, and incisional pain., ${ }^{724-26,30}$ Jacobaeus $^{15}$ described the direct visual inspection of the pleural cavity in two patients with exudative pleuritis and termed the procedure "thorakoskopie." Video-assisted thoracoscopic surgery has since been used for lung resections, mediastinoscopy, and pericardectomy. ${ }^{9}$ Several studies have documented the benefits of decreasing access-related morbidity by using minimally invasive approaches, including thoracoscopy.,10 Thoracoscopic spine surgery can decrease postoperative pain and shoulder dysfunction, improve postoperative respiratory function, shorten hospital stay, and promote earlier ambulation compared with open surgery. $7,8,10,24$

\section{Indications for Thoracoscopic Spine Surgery}

Thoracoscopic spine surgery was initially used primarily for sympathectomy and thoracic discectomies. ${ }^{11,25,26}$ With the development of anterolateral plating systems for stabilization, spine surgeons began to perform corpectomies in the thoracolumbar spine by using thoracoscopic spine surgery. ${ }^{7}$ Many authors have used this type of surgery for

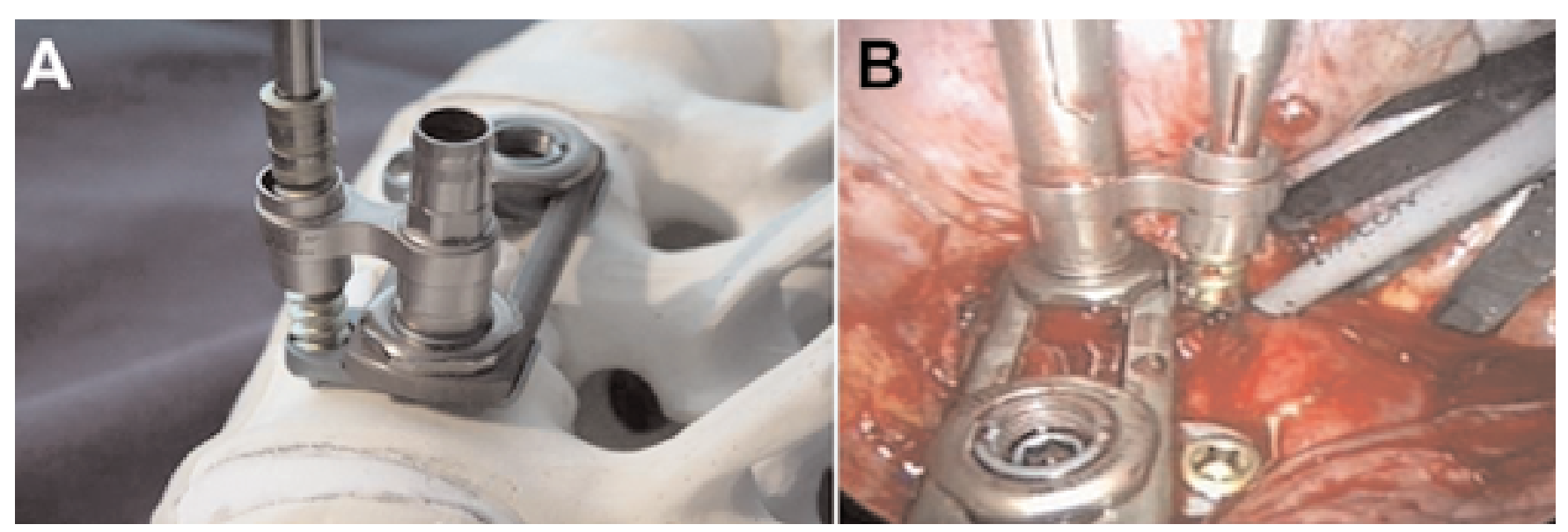

Fig. 10. A: Photograph showing placement of anterior screws in the spinal model. B: Intraoperative photograph showing endoscopic placement of anterior screws by using a specialized aiming device. 

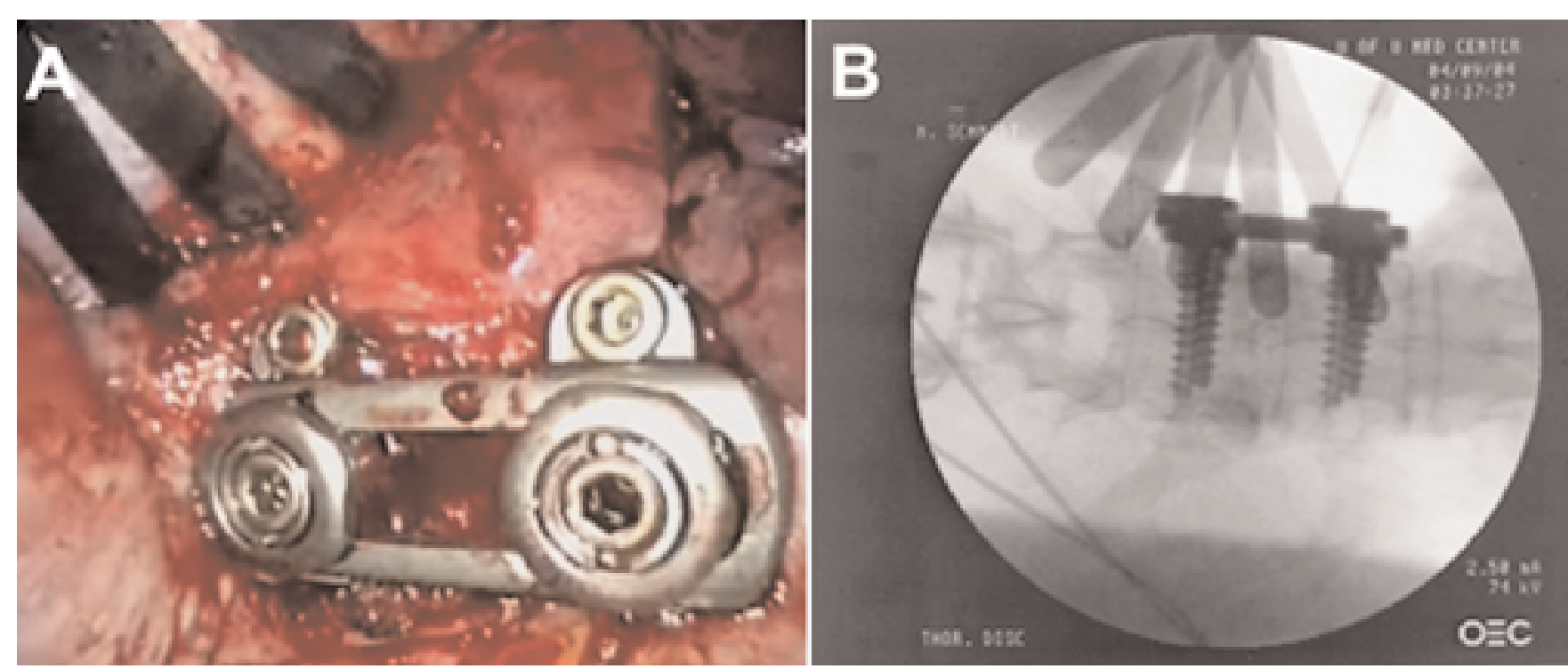

Fig. 11. A: Intraoperative photograph showing the endoscopic view of the final construct. B: Postoperative anteroposterior fluoroscopic image showing the screw plate construct in position.

multilevel thoracic discectomy for correction of spinal deformities, ${ }^{19}$ spinal reconstructive surgery, ${ }^{20}$ or removal of thoracic discs. 28

The use of thoracoscopic corpectomy and stabilization has also been reported for metastatic tumors and spinal frac- tures. ${ }^{20,27}$ Further development of endoscopic plating technology and surgical techniques has led to substantial improvements in thoracoscopic spine surgery. An increasing number of reports document the experience of spine surgeons with this surgical method for hyperhidrosis, thoracic

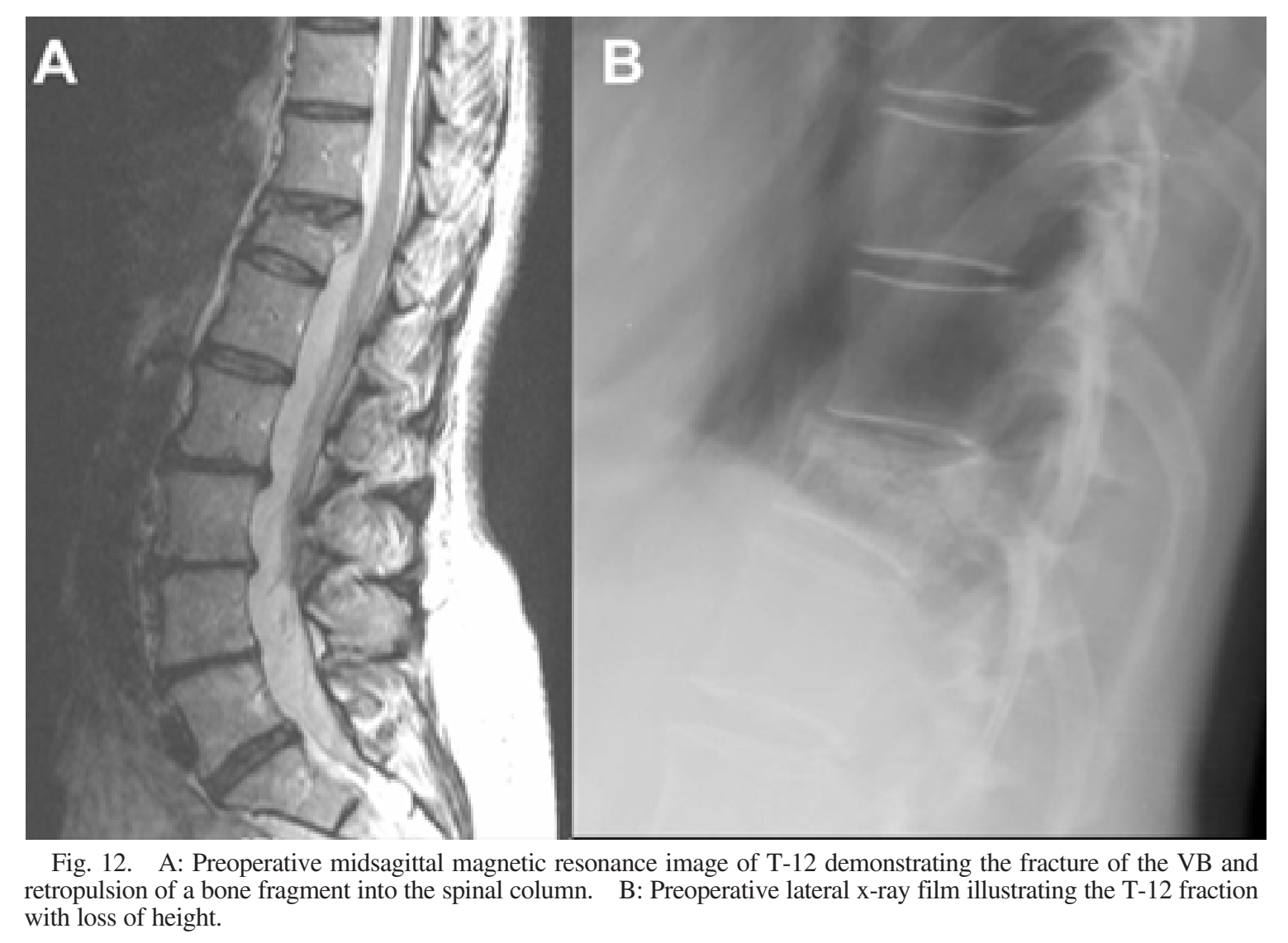


discectomy, adolescent scoliosis correction, and trauma. ${ }^{11,14,}$ 16,17,25-27,32 Beisse, et al., 5 recommended thoracoscopic spine surgery for unstable fractures of the thoracic and lumbar spine between T-3 and L-3, posttraumatic and degenerative spinal canal stenosis, ${ }^{3}$ discoligamentary instability, revision surgery and implant removal, and tumor and metastasis surgery with intervertebral body replacement. Today, key thoracolumbar spinal surgical techniques of discectomy, corpectomy, interbody reconstruction, and anterior lateral stabilization can all be performed endoscopically. ${ }^{7,22}$

\section{Contraindications and Complications}

Relative contraindications to thoracoscopic spine surgery include extensive adhesions, prior chest trauma, or surgery. Any of these factors may prolong the procedure or necessitate conversion to an open procedure. Several factors may delay the surgery but rarely prohibit it; these include hypoxemia, hypocoagulability, and cardiac abnormalities. Great care should be exercised in the presence of hypercarbia, but thoracoscopic spine surgery can still be undertaken. Severe respiratory failure may be an absolute contraindication, except in patients with trauma-related tension pneumothorax or massive hemothorax, in whom this surgery may be therapeutic.

Khoo, et al. ${ }^{16}$ reported a $1.2 \%$ overall operative conversion rate to open procedures in patients with trauma. They explained that the first two cases were among their first five procedures, which were affected by limited specialized spinal instrumentation and a learning curve. They reported one aortic injury during a revision thoracoscopic spine surgery for progressive loss of correction. The aortic injury occurred during scar tissue resection, which was repaired after conversion to an open procedure. They reported a complication rate of only $5.4 \%$ specifically related to the endoscopic approach, which compares favorably with the rate of $14 \%$ reported by other authors for open thoracotomy procedures. ${ }^{13,16}$ Reported complications included pleural effusion, pneumothorax, intercostal neuralgia, and transient L-1 sensory deficit. Furthermore, their overall complication rate was $8.55 \%$, which is less than one third of the $29 \%$ rate observed in the open series.

The complications of thoracoscopic surgery not related to the approach included deep wound infection (one case), splenic injury during chest tube placement (one case), and superficial wound infection (five cases). ${ }^{16}$ The authors concluded that their results were reasonably better than those associated with open procedures. Surgical time and blood loss during thoracoscopic treatment are comparable with those of standard open techniques. .,16,22 $^{5}$ The overall morbidity rate with thoracoscopic spine surgery is low, mainly because of the minimal surgical exposure and limited approach.

Other disadvantages of thoracoscopic spine surgery certainly include the steep learning curve and the need for single-lung ventilation. Patients with severe pulmonary dysfunction may not tolerate the prolonged periods of single-lung ventilation. Such patients might be better served with an extracavitary exposure or an open thoracotomy. Khoo, et al. ${ }^{16}$ reported a mean operative time of 6 hours in their first 30 to 40 cases. Development of new endoscopic instrumentation and increased experience reduced the mean operative time to 3 hours. These findings demonstrate the steep learning curve and the need for adequate training before attempting thoracoscopic spine surgery.

\section{CONCLUSIONS}

Under the right conditions, minimally invasive thoracoscopic spine surgery is a safe and effective alternative approach to thoracic and lumbar spine surgery. It can decrease operative time, blood loss, and duration of hospitalization, and it clearly decreases the morbidity associated with thoracolumbar surgeries, without compromising the safety and efficacy of the surgical procedure. This surgical method has been shown to be an appropriate one-stage procedure for endoscopic discectomy, corpectomy, spinal canal decompression, interbody reconstruction, and anterolateral fixation. Further well-designed prospective randomized studies will allow the medical community to determine the full benefit of this minimally invasive approach over the traditional open thoracotomy. As surgeons gain more experience with the procedure and new endoscopic instrumentation is developed, the indications for and application of thoracoscopic spine surgery will continue to expand.

\section{References}

1. Arlet V: Anterior thoracoscopic spine release in deformity surgery: a meta-analysis and review. Eur Spine J 9 (Suppl 1): S17-S23, 2000

2. Arnold PM, Baek PN, Bernardi RJ, et al: Surgical management of nontuberculous thoracic and lumbar vertebral osteomyelitis: report of 33 cases. Surg Neurol 47:551-561, 1997

3. Beisse R, Muckley T, Schmidt MH, et al: Surgical technique and results of endoscopic anterior spinal canal decompression. J Neurosurg Spine 2:128-136, 2005

4. Beisse R, Potulski M, Temme C, et al: Das endoskopisch kontollierte Zwerchfellsplitting. Ein minimal-invasiven Zugang zur ventralen Versorgung thorakolumbaler Frakturen der Wirbelsäule. Unfallchirurg 101:619-627, 1998

5. Beisse R, Potulski M, Bühren V: Endoscopic technique for the management of spinal trauma. Eur J Trauma 27:275-291, 2001

6. Birch BD, Desai RD, McCormick PC: Surgical approaches to the thoracolumbar spine. Neurosurg Clin N Am 8:471-485, 1997

7. Bühren V, Beisse R, Potulski M: Minimal-invasive ventrale Spondylodesen bei Verletzungen der Brust- und Lendenwirbelsäule. Chirurg 68:1076-1084, 1997

8. Caputy A, Starr J, Riedel C: Video-assisted endoscopic spinal surgery: thoracoscopic discectomy. Acta Neurochir (Wien) 134:196-199, 1995

9. Craig S: The evolution of thoracoscopic surgery, in Walker WS (ed): Video-Assisted Thoracic Surgery. Oxford: ISIS Medical Media, 1999

10. Cunningham BW, Kotani Y, McNulty PS, et al: Video-assisted thoracoscopic surgery versus open thoracotomy for anterior thoracic spinal fusion: a comparative radiographic, biomechanical, and histologic analysis in a sheep model. Spine 23:1333-1340, 1998

11. Dickman CA, Rosenthal D, Karahalios DG, et al: Thoracic vertebrectomy and reconstruction using a microsurgical thoracoscopic approach. Neurosurgery 38:279-293, 1996

12. Dietze DD Jr, Fessler RG, Jacob RP: Primary reconstruction for spinal infections. J Neurosurg 86:981-989, 1997

13. Faciszewski T, Winter RB, Lonstein JE, et al: The surgical and medical perioperative complications of anterior spinal fusion surgery in the thoracic and lumbar spine in adults. A review of 1223 procedures. Spine 20:1592-1599, 1995 


\section{Thoracoscopic surgery for spine decompression and stabilization}

14. Han PP, Kenny K, Dickman CA: Thoracoscopic approaches to the thoracic spine: experience with 241 surgical procedures. Neurosurgery 51 (5 Suppl):S88-S95, 2002

15. Jacobaeus H: Uber die Moglichkeit, die Zystoskopie bei der Untersuchung seroser Hohlen anzuwenden. Munch Med Wochenschr 57:2090-2092, 1910

16. Khoo LT, Beisse R, Potulski M: Thoracoscopic-assisted treatment of thoracic and lumbar fractures: a series of 371 consecutive cases. Neurosurgery 51 (5 Suppl):S104-S117, 2002

17. Kim DH, Jahng TA, Balabhadra RS, et al: Thoracoscopic transdiaphragmatic approach to thoracolumbar junction fractures. Spine J 4:317-328, 2004

18. Mack MJ, Regan JJ, Bobechko WP, et al: Application of thoracoscopy for diseases of the spine. Ann Thorac Surg 56: 736-738, 1993

19. Mack MJ, Regan JJ, McAfee PC, et al: Video-assisted thoracic surgery for the anterior approach to the thoracic spine. Ann Thorac Surg 59:1100-1106, 1995

20. McAfee PC, Regan JR, Fedder IL, et al: Anterior thoracic corpectomy for spinal cord decompression performed endoscopically. Surg Laparosc Endosc 5:339-348, 1995

21. McAfee PC, Regan JR, Zdeblick T, et al: The incidence of complications in endoscopic anterior thoracolumbar spinal reconstructive surgery. A prospective multicenter study comprising the first 100 consecutive cases. Spine 20:1624-1632, 1995

22. Muckley T, Schutz T, Schmidt MH, et al: The role of thoracoscopic spinal surgery in the management of pyogenic vertebral osteomyelitis. Spine 29:E227-E233, 2004

23. Newton PO, Wenger DR, Mubarak SJ, et al: Anterior release and fusion in pediatric spinal deformity. A comparison of early outcome and cost of thoracoscopic and open thoracotomy approaches. Spine 22:1398-1406, 1997

24. Potulski M, Beisse R, Bühren V: Die thorakoskopisch gesteurte Behandlung der "vorderen Säule." Technik und Ergebnisse. Orthopade 28:723-730, 1999
25. Regan JJ, Ben-Yishay A, Mack MJ: Video-assisted thoracoscopic excision of herniated thoracic disc: description of technique and preliminary experience in the first 29 cases. J Spinal Disord 11:183-191, 1998

26. Rosenthal D, Dickman CA: Thoracoscopic microsurgical excision of herniated thoracic discs. J Neurosurg 89:224-235, 1998

27. Rosenthal D, Marquardt G, Lorenz R, et al: Anterior decompression and stabilization using a microsurgical endoscopic technique for metastatic tumors of the thoracic spine. J Neurosurg 84:565-572, 1996

28. Rosenthal D, Rosenthal R, de Simone A: Removal of a protruded thoracic disc using microsurgical endoscopy. A new technique. Spine 19:1087-1091, 1994

29. Schmidt MH, Larson SJ, Maiman DJ: The lateral extracavitary approach to the thoracic and lumbar spine. Neurosurg Clin $\mathbf{N}$ Am 15:437-441, 2004

30. Visocchi M, Masferrer R, Sonntag VKH, et al: Thoracoscopic approaches to the thoracic spine. Acta Neurochir 140:737-744, 1998

31. Waisman M, Saute M: Thoracoscopic spine release before posterior instrumentation in scoliosis. Clin Orthop Relat Res: 130-136, 1997

32. Wong HK, Hee HT, Yu Z, et al: Results of thoracoscopic instrumented fusion versus conventional posterior instrumented fusion in adolescent idiopathic scoliosis undergoing selective thoracic fusion. Spine 29:2031-2039, 2004

Manuscript received October 15, 2005.

Accepted in final form November 15, 2005.

Address reprint requests to: Meic H. Schmidt, M.D., Department of Neurosurgery, University of Utah, 30 North 1900 East, Suite 3B409, Salt Lake City, Utah 84132. email: meic.schmidt@hsc.utah.edu. 